Article

\title{
Urban Growth, Real Estate Development and Indigenous Property: Simulating the Expansion Process in the City of Temuco, Chile
}

\author{
Francisco Maturana ${ }^{1, *(\mathbb{D})}$, Mauricio Morales ${ }^{2} \mathbb{D}$, Fernando Peña-Cortés ${ }^{3}$, Marco A. Peña ${ }^{2} \mathbb{D}$ and Carlos Vielma ${ }^{2}$ \\ 1 Instituto de Ciencias de la Tierra, Universidad Austral de Chile, Valdivia 5110566, Chile \\ 2 Departamento de Geografía, Universidad Alberto Hurtado, Santiago 8340578, Chile; mtmorale@uc.cl (M.M.); \\ mapena@uahurtado.cl (M.A.P.); cvielma@alumnos.uahurtado.cl (C.V.) \\ 3 Laboratorio de Planificación Territorial, Departamento de Ciencias Ambientales, Universidad Católica de \\ Temuco, Temuco 4781312, Chile; fpena@uct.cl \\ * Correspondence: francisco.maturana@uach.cl
}

check for updates

Citation: Maturana, F.; Morales, M.; Peña-Cortés, F.; Peña, M.A.; Vielma, C. Urban Growth, Real Estate Development and Indigenous Property: Simulating the Expansion Process in the City of Temuco, Chile. ISPRS Int. J. Geo-Inf. 2021, 10, 101. https://doi.org/10.3390/ijgi10020101

Academic Editors: Wolfgang Kainz and Géraldine Del Mondo

Received: 22 January 2021

Accepted: 19 February 2021

Published: 22 February 2021

Publisher's Note: MDPI stays neutral with regard to jurisdictional claims in published maps and institutional affiliations.

Copyright: (c) 2021 by the authors. Licensee MDPI, Basel, Switzerland. This article is an open access article distributed under the terms and conditions of the Creative Commons Attribution (CC BY) license (https:/ / creativecommons.org/licenses/by/ $4.0 /)$.

\begin{abstract}
Urbanization is spreading across the world and beyond metropolitan areas. Medium-sized cities have also undergone processes of accelerated urban expansion, especially in Latin America, thanks to scant regulation or a complete lack thereof. Thus, understanding urban growth in the past and simulating it in the future has become a tool to raise its visibility and challenge territorial planners. In this work, we use Markov chains, cellular automata, multi-criteria multi-objective evaluation, and the determination of land use/land cover (LULC) to model the urban growth of the city of Temuco, Chile, a paradigmatic case because it has experienced powerful growth, where real estate development pressures coexist with a high natural value and the presence of indigenous communities. The urban scenario is determined for the years 2033 and 2049 based on the spatial patterns between 1985 and 2017, where the model shows the trend of expansion toward the northeast and significant development in the western sector of the city, making them two potential centers of expansion and conflict in the future given the heavy pressure on lands that are indigenous property and have a high natural value, aspects that need to be incorporated into future territorial planning instruments.
\end{abstract}

Keywords: simulation; Markov chains; cellular automata; multi-criteria analysis; geographic information systems

\section{Introduction}

According to the United Nations [1], the impacts of urbanization can be seen practically all over the world and, by 2050 , over $60 \%$ of the population is projected to be urban, generating changes in the ways in which territories are occupied worldwide. Thus, beyond their size, territories are faced with remarkable mutations implying powerful advances in urban development in all dimensions, such as infrastructure, housing, services, and others, generating an urban landscape that is easy to perceive but extremely difficult to delimit, plan, and project.

One way to understand and respond to these phenomena is through the so-called "new science of cities", which has become a benchmark for modeling and analyzing them. For Batty [2], these new tools allow for representing, analyzing, simulating, forecasting, and creating urban structures. The above is in the context of defining cities as complex objects with different temporal and spatial scales that, despite their difficult characterization, have a certain logic that allows them to be analyzed [3].

These modeling possibilities are based on the complexity of cities' internal processes using geo-simulations [4], in which traditional stochastic models based on cellular automata, Markov chains, and multi-criteria evaluation give a fuller understanding of the effects of human activity on urbanization and environmental deterioration processes $[5,6]$. 
Geo-simulation is built on expanding computing capacities, geographic information systems, and other spatial programs and statistical packages that have not only allowed understanding cities' past growth and the changes in adjacent land cover [7], but also allow for prospecting future changes and speeds, fundamental aspects for developing more effective planning tools, valuing and protecting particularly fragile ecosystems [8], and in that way contributing to attenuating or mitigating deterioration processes in the natural system, or contributing to disaster risk management in urban areas $[9,10]$.

Modeling approaches have allowed different scales of analysis to be addressed, allowing behaviors to be modeled in mega cities [11] or in countries with greater concern for the processes that take place in their territories. This is the case with European nations, which have developed a wide range of models to understand these phenomena [12], thus allowing the driving forces that lead urbanization processes as accelerated processes of change in land use/land cover (LULC) to be analyzed [13]. Indeed, urban area simulation models are based on predictive variables such as historical LULC trends, the configuration of transport networks, or access to a city's work center [14].

In terms of the applicability of spatially explicit models or geo-simulation processes, metropolitan areas and developed countries are not the only ones facing constant changes from the dizzying speed of urbanization that need to be measured [15], but other smaller cities located in Latin America, for example, are also undergoing significant change that affects and determines their spaces and surroundings, and it is in this context that mediumsized urban entities or intermediate cities emerge [16]. They have direct links with their rural areas, configuring different degrees of centrality in their regional spaces and acting as important centers in terms of politics, services, social interaction, and connectivity, and administrative infrastructure $[17,18]$.

Thus, as is the case with metropolitan areas, medium-sized cities have been under real estate development pressures and show similar complexities as large cities, both in terms of their virtues-such as better access to specialized services and the infrastructure produced by agglomeration economies-as well as the problems, such as pollution, congestion, and uncontrolled expansion, among others. This is why it is important to study them, considering the contributions that urban science models can make to territorial planning or management processes.

\section{Background}

Chile is a paradigmatic case in Latin America, with an urban population of over $87 \%$ [19], an economic model with a powerfully neoliberal hallmark, a real estate market with weak regulation, and where intermediate cities and regional capitals have played a role as spaces that catalyze the needs of the territories closest to them [20].

The city of Temuco is an interesting case study due to its rapid process of metropolization and its high natural and cultural value [21]. It is located in the Araucanía Region (see location in Figure 1) and, according to the INE (2017), contains practically $40 \%$ of the total regional population, surpassing the city that follows closest threefold and fostering a high dependence on services and infrastructure [22]. At the same time, in Temuco, there are phenomena such as segregation and impoverished areas [23] and a large indigenous population of Mapuche origin. In fact, the Araucanía Region concentrates the second-largest population of this people after the national capital and $11 \%$ of Temuco's inhabitants declare themselves as belonging to the Mapuche people. 


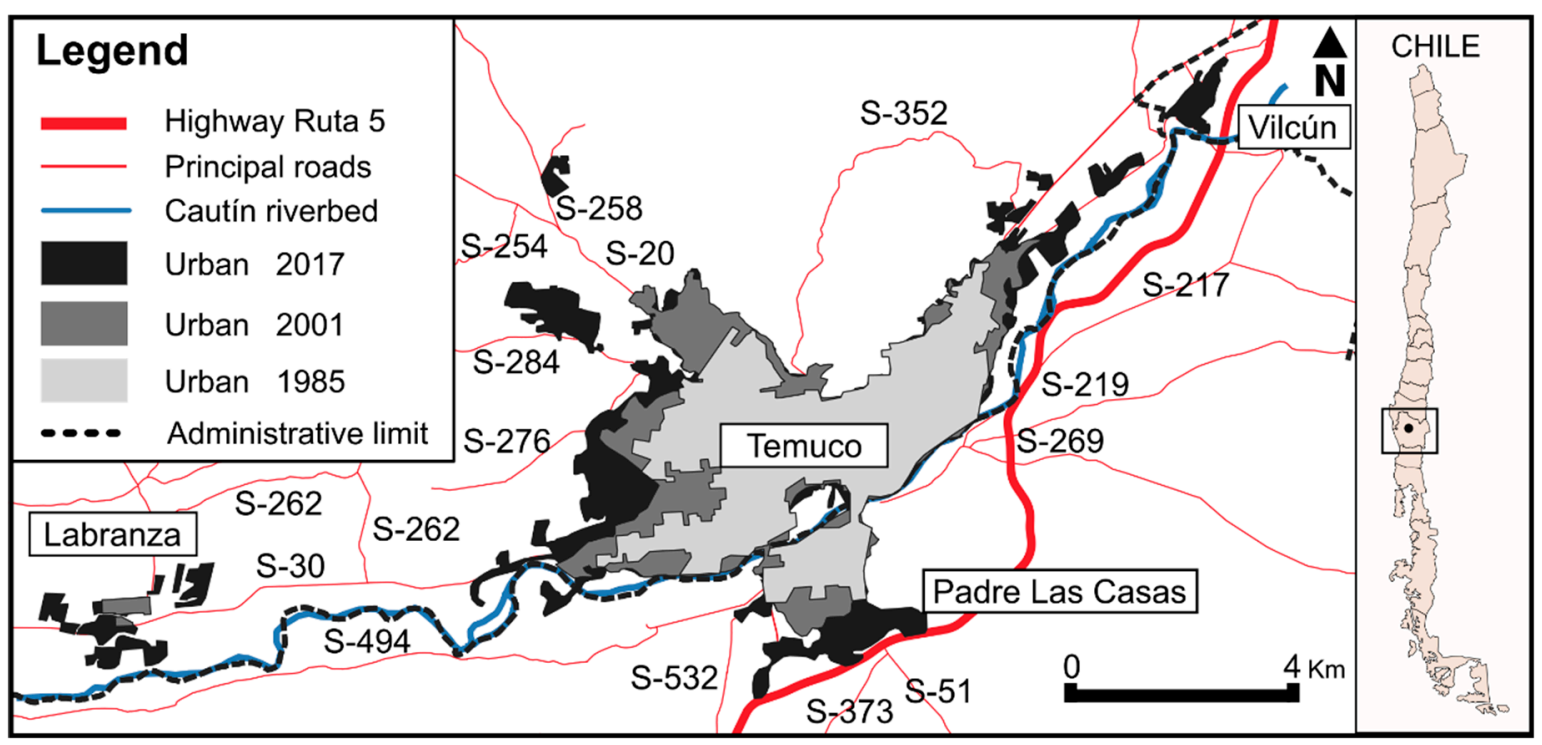

Figure 1. Study area and urban growth of the city of Temuco between 1985 and 2017. Source: Authors' compilation.

The presence of the Mapuche population is relevant given its rising demands to recover lands, recognition as a nation, and other historical claims arising from the depletion of their property dating back to the process of consolidating the Chilean nation-state in the late 19th century with the so-called 'pacification of Araucanía', a military campaign that killed and reduced Mapuche communities so the Chilean state could annex the current territories in Araucanía, among others [24].

In addition, in terms of planning, Temuco underwent unsuccessful processes of updating both the Municipal Zoning Plan (PRC, Spanish acronym for Plan Regulador Comunal) as well as the Intermunicipal Zoning Plan (PRI, Spanish acronym for Plan Regulador Intercomunal), regulatory urban land use and regulation tools that were developed in a context of strong real estate development pressure and one in which lands whose owners are Indigenous Communities under Law 19,253 cannot be rented, provided in gratuitous bailment, or assigned to third parties for their use, enjoyment, or administration. This is a restriction that has not been fully respected, as often there is no real record of domain or registration of such lands, creating conflicts over the use of space.

In addition to the elements mentioned are other aspects that also entail tremendous planning challenges in terms of population dynamics and a growing vehicle fleet. Regarding the former, it had 189,994 inhabitants in 1998 and 358,541 in the 2017 census (including the agglomerated municipalities of Temuco and Padre Las Casas). That is, it practically doubled its population in the last 35 years. As far as the latter is concerned, it had 42,548 vehicles in 2001 and 98,430 in 2018, thus more than doubling the number in less than 20 years. Both situations pose challenges in terms of infrastructure, services, quality of life, and environmental quality in the city.

Given this background, there is a need to reflect on the dynamics of this city and its not entirely planned urban expansion, which has revealed the urgent need for studies on the territory to achieve more sustainable urban development, understanding this in its broadest sense by incorporating the different dynamics and stakeholders immersed in it.

For this reason, this article explores changes in LULC in the city of Temuco to generate a simulation of built surface through to 2049 and in that way contribute to the debate on the areas that should be incorporated in the city's future planning, at least in terms of urban limits. To this end, the land cover between 1985 and 2017 was characterized, after which future urban growth in the city was simulated between 2017 and 2049 by analyzing the resulting spatial patterns in addition to the projected changes. 


\section{Materials and Methods}

\subsection{Study Area}

According to the 2017 population census, the city of Temuco in the Araucanía Region has a population of around 320,000 inhabitants. The urban area is composed of the urban areas in the municipalities of Temuco, Padre Las Casas, and Vilcún (see Figure 1).

The methodology of this work is summarized in Figure 2, after which the detail of each of the aspects addressed is presented.

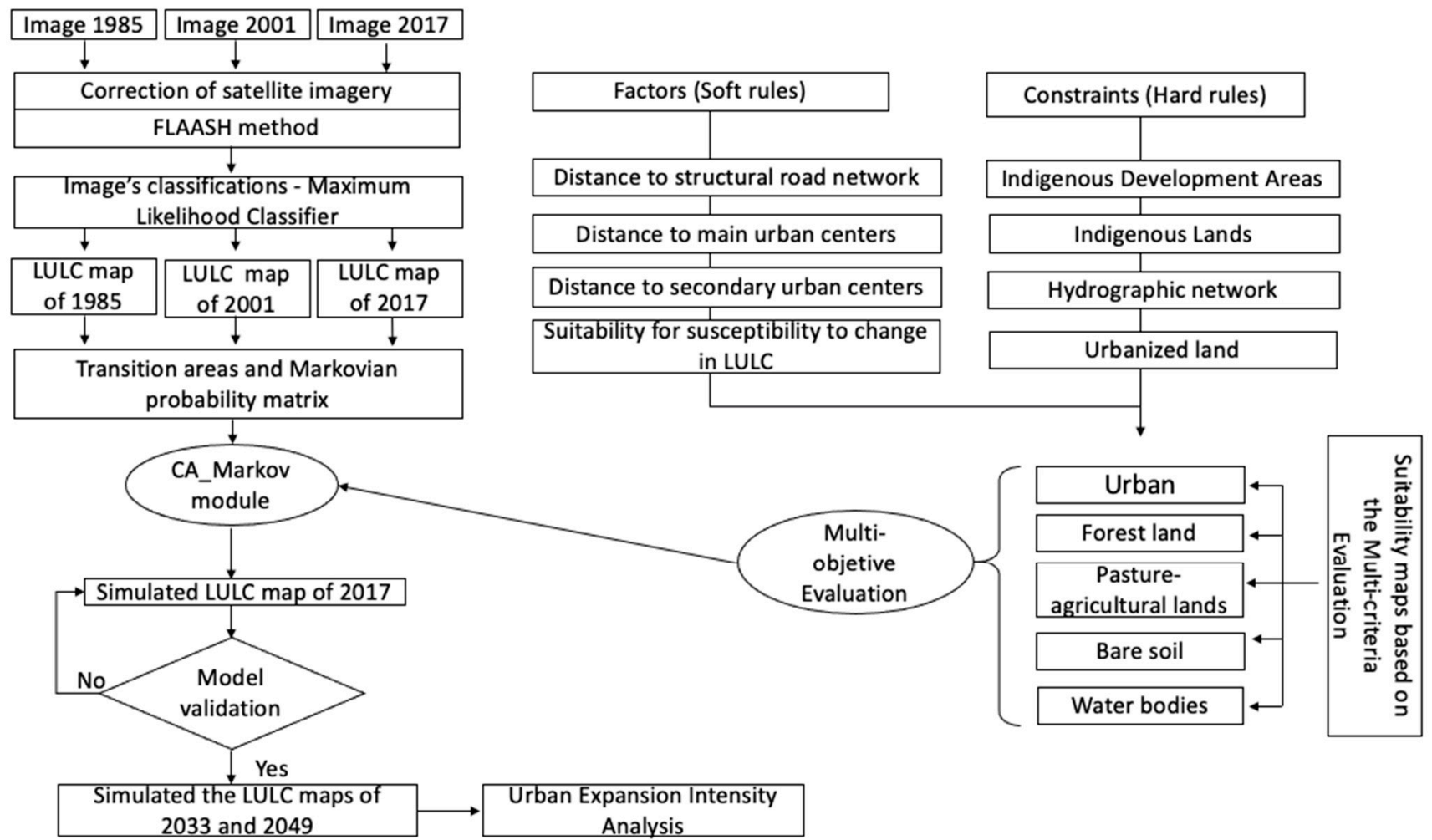

Figure 2. Summary of methodological model. Source: Authors' compilation.

This section may be divided by subheading. It seeks to provide a concise and precise description of the experimental results, their interpretation, and the experimental conclusions that can be drawn.

\subsection{Detection of Changes in Land Uses and Covers between 1985 and 2017}

This work uses optical satellite images to simulate Temuco's urban growth through to 2049, based on the period from 1985 to 2017 (see complete sequence of the method in Figure 2). The images were acquired by the Landsat-5, -7 and -8 spacecraft from 1985, 2001 and 2017, respectively, and downloaded from the Earth Explorer service (https: / / earthexplorer.usgs.gov/ (accessed on 21 February 2021)) of the US Geological Survey (Table 1). All images correspond to radiometrically calibrated and orthorectified products (Level-1 terrain precision, L1TP) whose at-sensor radiances were later converted into surface reflectance using the Fast Line-of-sight Atmospheric Analysis of Spectral Hypercubes (FLAASH) atmospheric corrector, available in Environment for Visualizing Images (ENVI) 5.3@ (Exelis Visual Information Solutions Inc., Broomfield, EE.UU.). 
Table 1. Main description of the satellite images used. Source: Authors' compilation.

\begin{tabular}{ccccc}
\hline Satellite/Sensor & $\begin{array}{c}\text { Image } \\
\text { Acquisition } \\
\text { Date } \\
\text { (yy/mm/dd) }\end{array}$ & $\begin{array}{c}\text { Spatial } \\
\text { Resolution } \\
(\mathbf{m})\end{array}$ & $\begin{array}{c}\text { Spectral } \\
\text { Resolution } \\
\text { (\#Bands) }\end{array}$ & Scene ID \\
\hline Landsat5/MSS & $1985 / 02 / 10$ & 30 & 4 & LM52330871985041AAA03 \\
\hline $\begin{array}{c}\text { Landsat- } \\
7 / \text { ETM+ }\end{array}$ & $2001 / 03 / 18$ & 30 & 6 & LE72330872001077EDC00 \\
\hline $\begin{array}{l}\text { Landsat- } \\
\text { 8/OLI }\end{array}$ & $2017 / 03 / 06$ & 30 & 6 & LC82330872017065LGN01 \\
\hline * Broad-bands within the optical spectrum, excluding the panchromatic band. &
\end{tabular}

To increase the inherent low spectral dimensionality of the Landsat-5 image and in that way improve its ability to discriminate the LULC of interest, the pixels' spectral reflectance curves were subjected to two transformations: (1) continuum removal [25] and (2) first derivative [26]. The former was calculated by dividing the pixel's spectral reflectance curve by its convex envelope, which results from tracing straight line segments that connect the maxima of the spectral reflectance curve.

$$
C R=\left(\frac{\rho}{C}\right)
$$

where:

$C R=$ continuum removal curve

$\rho=$ spectral reflectance

$C=$ line that connects the reflectance maxima

The resulting values are equal to 1.0 where the continuum and the original spectra match, and less than 1.0 where absorption features occur.

Meanwhile, the first derivative reflectance highlights relative differences on the original spectral curve by calculating their slope around a given band using the central finite differences method (forward and backward differences were used for the first and last image bands).

$$
\frac{\left(\rho_{(t+1)}-\rho_{(t-1)}\right)}{\left(\lambda_{(t+1)}-\lambda_{(t-1)}\right)}
$$

where:

$\rho=$ spectral reflectance of an adjacent band

$\lambda=$ spectral wavelength of an adjacent band

The features resulting from both transformations were added to the original spectral dimensionality of the Landsat- 5 image for use in the subsequent LULC classification.

Image classifications were performed using the well-known maximum likelihood supervised procedure, where urban land use, forest land cover, pasture-agricultural lands (dense or sparse), bare soils, and water bodies were trained by manually selecting (if possible, temporally invariable) representative sites on each one of them (see Figure 2). Separability of the training-derived spectral curves was proven using the Jeffries-Matusita distance measure. All LULC classification maps were set to at an approximate scale of 1:30,000, which is appropriate for intermediate-sized cities in the Chilean context [27].

\subsection{Geo-Simulation of Changes in Land Use and Cover Using Cellular Automata and Markov Chains}

To apply a simultaneous simulation to model LULC changes in the city of Temuco, there was a need to obtain retrospective results of urbanization between 1985 and 2017 by means of spatial-temporal analysis of urban use. The proposed model includes multicriteria/multi-objective analysis, Markov chains and cellular automata techniques. The 
Land Change Modeler (LCM) in IDRISI 17.0 was used to fulfill this objective, which allows for integrating these techniques. With this model, we proceed to analyze the trends in land use and cover between 1985, 2001, and 2017 for each of the land uses and covers that are required as an input for the proposed simulation model.

\subsubsection{Multi-Criteria and Multi-Objective Evaluation}

To develop the simulation model, a multi-criteria/multi-objective evaluation was undertaken, with multi-criteria evaluation (MCE) understood to be the sum of the positive effects minus the negative effects of an activity or criterion assessed, and multi-objective evaluation (MOE) corresponding to the analysis of a series of activities or criteria and how they are configured in a host map that integrates all the criteria analyzed in the MCE [28]. Thus, MCE-MOE responds to the use of layers in the form of criteria in support of the urban growth projection for Temuco. This includes choosing both urban growth constraints as well as factors that boost it (see Table 2).

Table 2. Factors and constraints considered for MCE-MOE. Source: Authors' compilation.

\begin{tabular}{|c|c|c|c|}
\hline Criterion & Variable & Unit of Measure & Source \\
\hline \multirow{4}{*}{ Factors } & Distance to main urban centers & Meters & Authors' compilation based on 2017 Census. \\
\hline & Distance to secondary urban centers & Meters & Authors' compilation based on 2017 Census. \\
\hline & Distance to structural road network & Meters & Open Street Maps, 2019. \\
\hline & Suitability for susceptibility to change in land use/land cover & Normalized score & Authors' compilation. \\
\hline \multirow{4}{*}{ Constraints } & Indigenous Development Areas (ADI) & Hectares & CONADI, 2019. \\
\hline & Indigenous Lands & Hectares & CONADI, 2019. \\
\hline & Hydrographic network & Hectares & Library of the National Congress of Chile, 2018. \\
\hline & Urbanized land & Hectares & Authors' compilation based on 2017 Census. \\
\hline
\end{tabular}

Regarding the criteria that limit urban development (Boolean covers), the variable "Indigenous Development Areas" (ADI) reveals the direct relevance of Mapuche population sectors in the study area [29]. ADIs are areas where indigenous development will be focused, according to the provisions of Law 19,253, while "Indigenous Lands" are protected areas where an indigenous person or community resides. The hydrographic network and the land urbanized by 2017 was added to the above, based on the urban area that had already been consolidated, where there is zero probability that it will be urbanized again by the proposed model.

Regarding the factors, mainly those identified by the literature for the analysis of medium-sized Chilean cities were considered [30,31], such as "Distance to main urban centers", "Distance to secondary urban centers", "Distance to structural road network" and "Suitability for susceptibility to change in LULC". These factors were normalized between the values of 0 (least suitable) and 255 (most suitable) using a fuzzy logic method. With this, multi-objective maps were produced for each land use and cover analyzed. This process was performed using the Decision Wizard module of IDRISI 17.0.

In particular, the process detailed above enabled estimating the urban suitability map. Given its complexity and importance in the simulation model, weightings are estimated using paired comparison for each of the factors, which were subsequently analyzed using the analytical hierarchy process (AHP) [32]. This process is expressed in the following formula:

$$
\text { Urban suitability }=\sum_{j=1}^{4} w_{j} e_{i j}
$$

where:

$w_{j}=$ This is the weight or criterion of each $j$ factor product of the AHP.

$e_{i j}=$ value of each factor $i$ for each criterion $j$.

Thus, an initial urban suitability map is obtained for the MCE-MOE. With the rest of the suitability maps (pasture-agricultural lands, forest land cover, bare soils, and water bodies), simplified MCE were generated with fuzzy membership function between values 
0 (less suitable) and 255 (most suitable), which reflect the relative importance of the total uses/covers observed for the suitability analyzed. A total of six MCE maps were estimated based on LULC, which were subsequently added as a raster group file in IDRISI 17.0.

Once the land covers and the MCE-MOE were determined, a probability matrix was generated to make the projection, which entails considering at least two measurements in time, which for this case fall within the range 1985-2017 [14]. Using this scenario, a final image of the probability of transition changes in LULC through to 2049 was generated.

\subsubsection{Markov Chains and Cellular Automata}

Markov chains (MC) allow for projecting the spaces that will change cover from a cover state $A$ to a cover state $B$. The $\mathrm{MC}$ technique works considering that the spatial distribution of land covers is the direct result of the situation at a prior moment $(\mathrm{t}-1)$. Therefore, the model considers that a state is the linear result of its previous scenario [2,7]. For this point, the Markov module was run in IDRISI 17.0 using a proportional error of $15 \%$ to estimate the probability of transition for (i) a model validation scenario considering the probability of transition between 1985 and 2017, and (ii) a scenario that simulates the probability for the years 2033 and 2049, with the former being through the transition probability between 2001 and 2017 and the latter being a transition probability matrix between 1985 and 2017.

The last technique used was cellular automata (CA) for each of the previously estimated transition probability matrices. This process technically relates the previous state of the pixels to the state of neighboring pixels, based on the rules of transition for each land use and cover, where they take a given future status based on each pixel according to the land use/covers of the surrounding cellular automata based on their interactions, thus being able to spatially locate the pixels with a greater probability of change [33].

Mathematically, CA can be understood as follows: $C A \sim(S, T, N)$, where $S$ is the set of states land uses and covers, which change from to to t 1 according to their transition rules (T), and $\mathrm{N}$ represents the relationship of the central cell with its orthogonal neighbors. For this point, the CA_Markov module is run in IDRISI 17.0, simulating for the years 2017, 2033, and 2049 as a way of estimating the spatial changes that were calculated by the Markov Chains for each period, using a $5 \times 5$ proximity filter and $10 \mathrm{CA}$ iterations, which is the number that the IDRISI 17.0 program estimates by default.

For the model validation phase, the year 2017 was simulated considering the periods 1985 and 2001 for comparison with the LULC classification for 2017. For this, precision assessment measures were used for both maps (2017 observed and 2017 simulated), implementing the Kappa index of agreement (KIA) proposed by Pontius [34] and chi-square test statistics [9].

\subsection{Urban Expansion Intensity Analysis}

One way to analyze these results is through the dynamics inherent to the spatially explicit models and indicators that allow assessing expansion processes [35]. The proposed expansion intensity (EI) indicator was used as a tool that allows for comparing the intensity and speed of urban land expansion for the periods 2017-2033 and 2017-2049.

$$
E I=\frac{U_{t+n}-U_{t}}{A} \times \frac{1}{\Delta t} \times 100 \%
$$

where $E I$ corresponds to the Expansion Intensity Index, $U_{t}$ is the initial urban area in the study, $U_{t+n}$ corresponds to the final urban area under study, $A$ is the total area analyzed, and $\Delta t$ corresponds to the time interval analyzed. According to Zhang et al. [36], changes in urban expansion can be analyzed according to three types, which are low-speed expansion period $(0 \leq E I \leq 0.07 \%)$, medium-speed expansion period $(0.07 \leq E I \leq 0.10 \%)$, and high-speed expansion period $(E I \geq 0.10 \%)$. 


\section{Results}

The results were structured in three points. The first concerns validation of the model. The second analyzes the trends in land use and cover between 1985 and 2017, and the last simulates changes in land use and cover for the city of Temuco.

\subsection{Validation of the Simulation Model for the City of Temuco}

The 2017 LULC map was validated with the 2017 map simulated using the CA_Markov model. Table 3 shows an analysis based on the discrepancy between a reference map and one that was simulated using the chi-square test, where our hypothesis is that the observed LULC map is the same as the simulated LULC map.

Table 3. Validation of land use and cover, 2017 observed and simulated ${ }^{1}$.

\begin{tabular}{cccc}
\hline \multicolumn{4}{c}{ Chi-Square Test } \\
\hline LULC & OBS 2017 (O) & SIM 2017 (S) & (O-S)2/O \\
\hline Forest land cover & $19.1 \%$ & $27.4 \%$ & 0.04 \\
Pasture-agricultural & $72.7 \%$ & $56.5 \%$ & 0.04 \\
Bare soil & $0.9 \%$ & $8.7 \%$ & 0.70 \\
Urban land use & $6.8 \%$ & $6.2 \%$ & 0.00 \\
Water bodies & $0.5 \%$ & $1.2 \%$ & 0.01 \\
Total & $100 \%$ & $100 \%$ & 0.78 \\
\hline
\end{tabular}

${ }^{1}$ Note: $X^{2}=\Sigma\left(\right.$ reference LULC - simulated LULC) ${ }^{2} /$ reference LULC $=0.78 ; \mathrm{df}=4 ; X^{2}{ }_{0.95}(4)=9.49$. The information displayed in the columns "OBS 2017(O)" and "SIM 2017(S)" represents the individual percentage of each LULC used for the validation model.

However, the chi-square analysis only allows an overall view of the statistically significant correspondence between the land uses and covers observed and simulated for 2017. For this, the KIA analysis allows the level of agreement/disagreement between the observed LULC and the simulated LULC to be assessed, and Table 4 shows that there is an overall Kappa (Kno) of 0.69, which reflects a moderate level of aggregation.

Table 4. Kappa Index values for the proposed 2017 validation model. Source: Authors' compilation.

\begin{tabular}{cc}
\hline Indicator & Value \\
\hline Kno & 0.6852 \\
Klocation & 0.7714 \\
KlocationStrata & 0.7714 \\
Kstandard & 0.5268 \\
\hline
\end{tabular}

In this regard, according to the criteria established by Nath et al. [9], the Klocation statistics are the measure to be considered to validate the LULC simulation, and in that way predict location, which in this case study is 0.77 , considered moderate aggregation (see Table 4).

The results of the validation carried out through KIA provide information on the agreement/disagreement components of the CA_Markov model, with error due to the $16.9 \%$ quantity (DisagreeQuantity) and error due to the 0.8 assignment (DisagreeGridcell) (see Table 5). In addition, the agreement level based on the specification of the level of the grid cell for each LULC category (AgreementGridcell) is $28 \%$, which is consistent with the moderate levels observed in Kno and Klocation (see Table 5). 
Table 5. Results of the agreement/disagreement classification analysis for reference and simulated. Source: Authors' compilation.

\begin{tabular}{cc}
\hline Agreement/Disagreement & Percentage \\
\hline AgreementChance & 20.00 \\
AgreementQuantity & 26.79 \\
AgreementStrata & 0.00 \\
AgreementGridcell & 28.03 \\
DisagreeGridcell & 0.83 \\
DisagreeStrata & 0.00 \\
DisagreeQuantity & 16.88 \\
\hline
\end{tabular}

Thus, the chi-square test shows that the statistical value is lower than the critical value. Hence, the null hypothesis is rejected, and it is possible to observe that there are differences between the simulated and reference LULC maps in 2017. However, this is consistent with the results of the analysis of KIA values, which range between the values 0 (zero agreement) and 1 (perfect agreement) [27], where one can see that there are moderate levels of accuracy between the reference map and the simulated map.

\subsection{Trends in Land Use and Cover Between 1985 and 2017}

Figures 1 and 3 express the process of urban expansion and land cover changes between 1985 and 2017. As can be seen, both forest as well as urban surface areas expanded, by $50.2 \%$ and $96.1 \%$, respectively. However, the areas assigned to pasture-agricultural land zones, water bodies, and bare soil decreased, with the latter falling by $85.9 \%$ (see Figure 3 ).

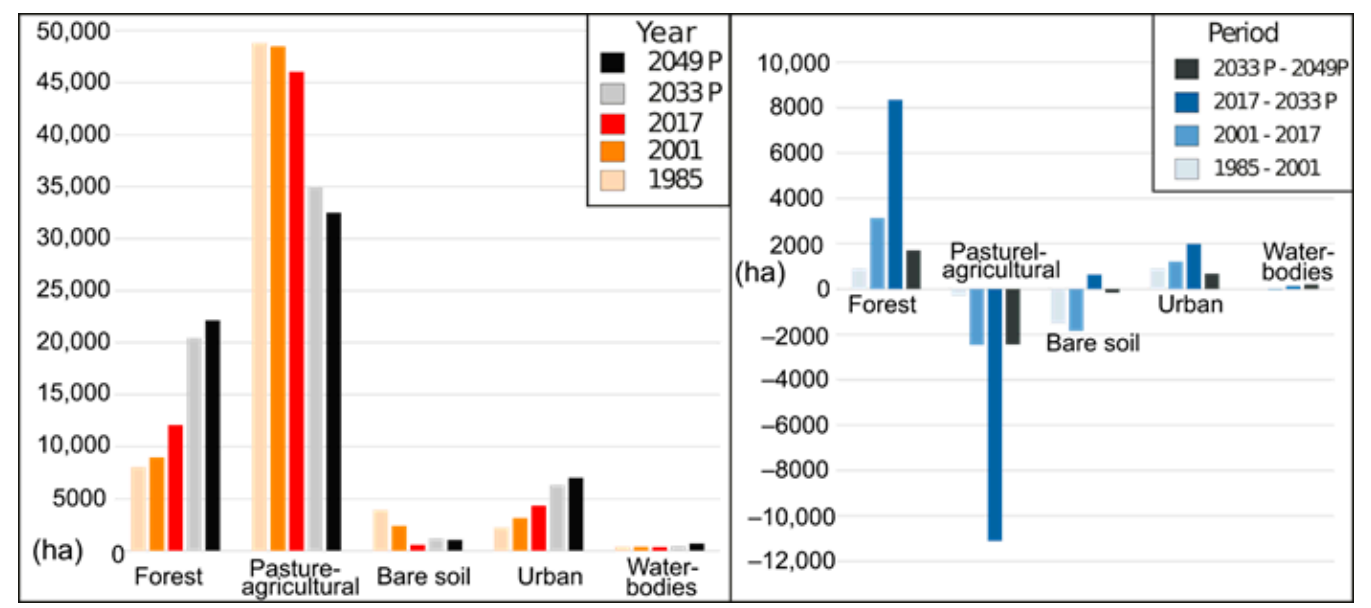

Figure 3. Distribution of the area occupied by LULC in the city of Temuco, 1985-2049. Source: Authors' compilation. Note: P: Refers to simulated values.

Regarding the areas that expanded, and considering the first period from 1985 to 2001, the most significant was urban land use, which grew by 921 ha, or a $41.6 \%$ increase in land cover compared to 1985 (see Figure 3). For its part, forest land cover increased by $11.3 \%$. In addition, it is important to mention the emergence of Labranza as an urban center, which despite not being contiguous with the city of Temuco, became a new spatial reference in the vicinity of the city, something that did not exist in 1985. As far as decreases in this same period are concerned, bare soil experienced a $38.7 \%$ reduction compared to the surface area in the initial year. While the other two covers were diminished (pasture-agricultural land and water bodies), their changes were marginal: 0.6 and $1.7 \%$, respectively.

In the period spanning 2001 to 2017 (see Figure 3), the most significant change was the drop in the pace of urban land growth, which expanded by $38.5 \%$, or an additional 1206 hectares. For its part, forest land cover increased by 35\%, thus expanding its spatial influence by 3130 hectares. Regarding LULC that declined, pasture-agricultural lands, bare 
soils, and water bodies were the most affected by the transition in LULC. Of these, bare soil was the one that saw its surface area drop the most, $77 \%$, while pasture-agricultural land and water bodies were down by $5.1 \%$ and $8.4 \%$, respectively.

In sum, the change in bare soil stands out in the evolution over time between 1985 and 2017. It declined by a total of $85.9 \%$ since 1985 ( 3355 ha), which, beyond its disappearance in terms of cover, indicates significant dynamism in terms of change from one cover to another. For their part, water bodies and pasture-agricultural cover showed less than $10 \%$ change. Urban cover stands out among those which increased, growing by almost twice what it represented in 1985 (96.1\%), or an increase of 2127 hectares.

In particular, urban land use corresponding to the physical area of Temuco mainly expanded toward the northeast (Vilcún sector) and south-west (Labranza sector) between 1985 and 2017. It is important to highlight the emergence of Labranza as a hub in the urban network without being a direct branch of it. It grew from 33 ha in 2001 to 204 ha in 2017, which shows the sector's dynamism in just 16 years. However, this situation was predictable, to a great extent thanks to the construction of a dual carriageway road that began in 2011, in addition to the fact that Labranza is a sector that was chosen for the construction of social housing for people who could not find housing solutions near Temuco due to high property prices [37]. This is a classic way of providing housing solutions in Latin American countries and especially in Chile, causing high levels of segregation and precarious living conditions under the auspices of the state itself [38].

\subsection{Simulation of Changes in Land Use and Cover for the City of Temuco}

The results of the Markov chains and the Multi-criteria/multi-objective evaluation were used to simulate land use and cover for 2033 and 2049, with the transitions obtained between 2001 and 2017 used for the former and the transitions between 1985 and 2017 for the latter. Figure 4 shows the suitability maps for each objective evaluated, which correspond to each land use and land cover and where one can observe that, for the objective of urban suitability, the paired comparison matrix from the AHP allowed the weights or eigenvector for each factor analyzed to be obtained, with the distance from the main urban center and distance to the secondary urban center having a $74.5 \%$ impact (see Table 6).

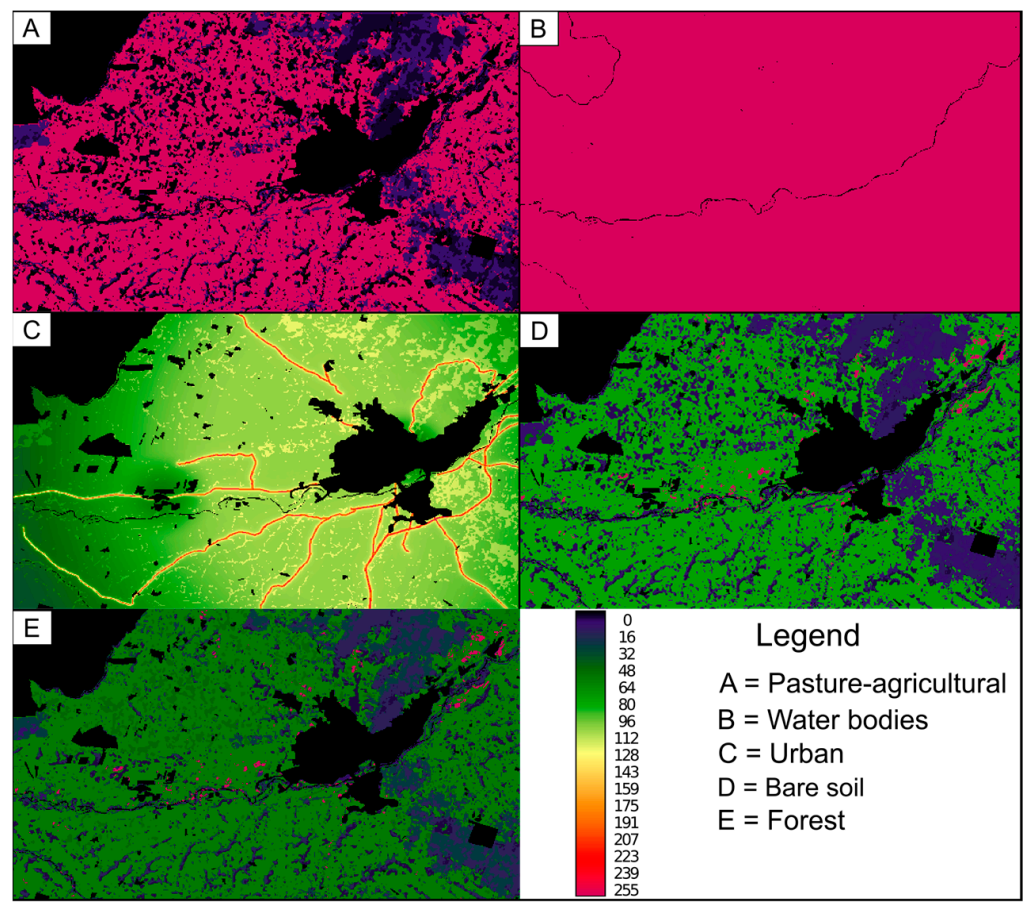

Figure 4. Suitability maps based on multi-criteria evaluation. Source: Authors' compilation. 
Table 6. Paired comparison matrix for determining weights for the MCE of the urban suitability objective. Source: Authors' compilation.

\begin{tabular}{|c|c|c|c|c|c|}
\hline & $\begin{array}{l}\text { Distance to } \\
\text { Main Urban } \\
\text { Center }\end{array}$ & $\begin{array}{c}\text { Distance to } \\
\text { Secondary } \\
\text { Urban Center }\end{array}$ & $\begin{array}{c}\text { Distance to } \\
\text { Structural Road } \\
\text { Network }\end{array}$ & $\begin{array}{l}\text { Suitability for } \\
\text { Susceptibility to } \\
\text { Change in Land } \\
\text { Use/Land Cover }\end{array}$ & Weight \\
\hline Distance to main urban center & 1 & 2 & 3 & 4 & 0.4673 \\
\hline Distance to secondary urban center & $1 / 2$ & 1 & 2 & 3 & 0.2772 \\
\hline Distance to structural road network & $1 / 3$ & $1 / 2$ & 1 & 2 & 0.1601 \\
\hline $\begin{array}{l}\text { Suitability for susceptibility to change in } \\
\text { land use/land cover }\end{array}$ & $1 / 4$ & $1 / 3$ & $1 / 2$ & 1 & 0.0954 \\
\hline
\end{tabular}

Considering the scenarios in 2033 and 2049, one can observe sustained growth in the urban area, expanding by an average of $44 \%$ between the two periods compared to 2017, equivalent to an average of 2328 hectares that are to be incorporated into the urban area of Temuco. Furthermore, one can see that there is a $59.2 \%$ average increase in forest cover compared to 2017 (see Figure 3).

According to the data contained in Figure 3, the city of Temuco will grow physically by around 1989 ha and reach a total of 6328 hectares by 2033, of which 293.9 hectares will be in Labranza, which in turn will represent $4.5 \%$ of the total urban area of the city of Temuco (see Figures 4 and 5). As was the case with the trend observed between 1985, 2001, and 2017, growth toward the northeast, in the Cajón sector (municipality of Vilcún) and southwest (Labranza sector) of the municipality of Temuco is maintained.

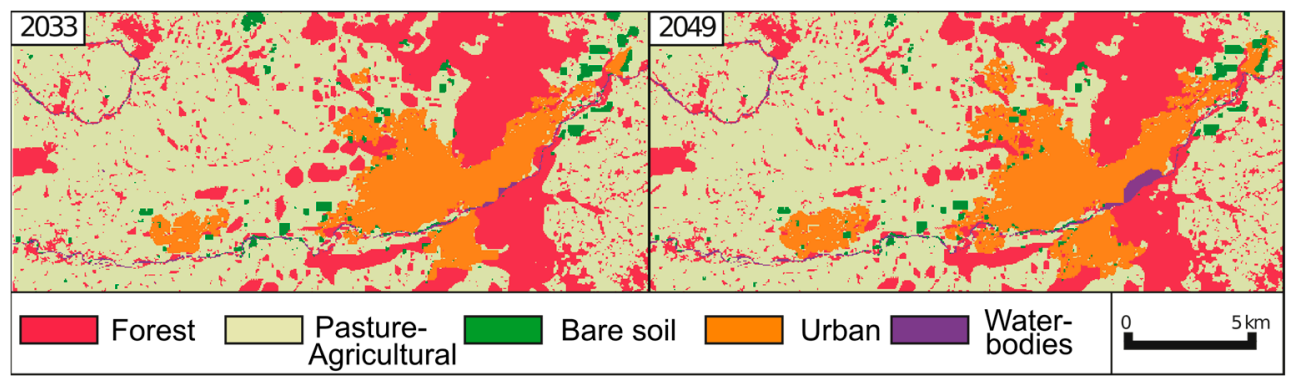

Figure 5. Simulated scenarios in 2033 and 2049. Source: Authors' compilation.

For the second scenario simulated to 2049, one can see how urban cover will have increased by 2667 hectares from what it was in 2017, a $42.2 \%$ change, whose differential is $54 \%$ less than the observed growth rate between 1985 and 2017. Thus, the model simulated through to 2049 shows a slower growth rate than the comparative one with the LULC, but it begins to incorporate new areas in the sectors of Padre Las Casas (712.5 hectares) and Labranza (601.7 hectares).

The Urban Expansion Intensity (EI) Index calculated for Temuco reveals an uneven situation in the pace of urban growth through to 2049. When considering changes in urban areas between 2033 and 2049 compared to 2017, one can see that the urban areas of Vilcún (Cajón sector), Padre Las Casas, and Labranza show growth rates of $0.009 \%$, which is considered low. However, the urban area of the municipality of Temuco shows an average growth rate of $0.13 \%$, which is considered a medium expansion rate. This last expansion trend is consistent when evaluating the sum of all urban areas that comprise the city of Temuco (see Table 7). 
Table 7. Expansion Intensity (EI) Index for the city of Temuco through to 2033 and 2049. Source: Authors' compilation.

\begin{tabular}{|c|c|c|c|c|c|c|c|}
\hline \multirow{2}{*}{ Urban Area } & \multirow{2}{*}{$\begin{array}{l}\text { Area in } \\
2017 \text { (ha) }\end{array}$} & \multicolumn{2}{|c|}{$\begin{array}{c}\text { Expansion Area } \\
\text { (Hectares) }\end{array}$} & \multicolumn{2}{|c|}{$\begin{array}{c}\text { EI Index } \\
2017-2033\end{array}$} & \multicolumn{2}{|c|}{ EI Index 2017-2049 } \\
\hline & & 2033 & 2049 & $\%$ & $\begin{array}{l}\text { Explanation } \\
\text { (Expansion) }\end{array}$ & $\%$ & $\begin{array}{l}\text { Explanation } \\
\text { (Expansion) }\end{array}$ \\
\hline Temuco & 3479.6 & 5183.7 & 5506.9 & 0.168 & high-speed & 0.100 & medium-speed \\
\hline Padre Las Casas & 582.1 & 663.5 & 712.5 & 0.008 & low-speed & 0.006 & low-speed \\
\hline Labranza & 201.1 & 293.9 & 601.7 & 0.009 & low-speed & 0.020 & low-speed \\
\hline Vilcún (Cajón sector) & 76.1 & 186.5 & 184.9 & 0.011 & low-speed & 0.005 & low-speed \\
\hline Temuco city & 4338.9 & 6327.5 & 7006.1 & 0.196 & high-speed & 0.132 & medium-speed \\
\hline Total area of study & 63.360 & & & & & & \\
\hline
\end{tabular}

The simulation model proposed for the years 2033 and 2049 shows that urban growth will tend to grow more strongly toward the periphery, with an emphasis on the Labranza sector, which is consistent with the development of the dual carriageway road parallel to the street 1 Norte with the new street 1 Sur. Thus, connectivity between the regional capital and the coastal sector (Temuco-Nueva Imperial-Carahue) is being improved and the passage through Labranza has benefited it greatly.

This is not a random phenomenon, as the social housing construction policy has focused heavily on the area, as noted earlier, in addition to new real estate development projects aimed at middle class sectors and the future construction that is sure to be promoted along the road. According to the 2002 and 2012 censuses, $16 \%$ of total regional mobility to Temuco came from these territories, a process that is sustained on the dual carriageway to stimulate urban growth and expansion.

\section{Discussion}

The results presented in the previous section show some trends that need to be considered in current and future planning of the city and which are summarized in Figure 6. In the case of Labranza, one way to highlight its growth is through its increase in surface area. If we take 2049 as the reference year, Temuco alone does not manage to double its area, but Labranza will increase its surface area by about four times, with what was observed in 2017 representing $26 \%$ of what it will be in 2049 , when it will be built as a compact unit. The city of Temuco is expected to grow by 2667.2 ha by 2049 , from which we can conclude that it is currently at around $61.9 \%$ of what it will be in 2049 .

A second sector that will experience significant growth is the sector of Cerro Mariposa, or the road to "Las Vegas de Chivilcán" toward the north of the city, near Cerro Nielol. There is currently a dynamic property market aimed at leisure plots, but this will change in the future. Indeed, if through to 2033 only Labranza can be considered as a non-contiguous hub of the Temuco system, in 2049 new signs of urbanization will appear in the areas already mentioned, which would exert pressure not only in terms of diffuse real estate development, but also in environmental terms, being located near one of the city's main wetlands, whose recognition the municipality requested in the framework of the Urban Wetlands Act that has been approved in the country.

In addition, continuing along Route S-258, which is the extension of Pedro de Valdivia Avenue (see Figure 1), the social housing developments built as a sort of archipelago will also contribute to these dynamics. If the growth trend is projected in the way that the model indicates (see Figure 6), Temuco will be faced with a scenario of increasingly discontinuous growth, in an amoeba shape and not in a compact form, something already seen in other intermediate cities in Chile $[27,30]$ and, while perhaps to be expected, something that goes against all sustainability aspects contained in the National Urban Development Policy released in 2014. In terms of planning urban space, the need to create a new municipality has even been considered, a matter that political circles have taken into account by submitting a request to this effect. In fact, since 2012 a social movement in favor of creating the municipality of Labranza has emerged and has organized different activities 
aimed at becoming an autonomous unit. However, the cost of the public apparatus and scant political capital could be some of the elements holding back these aspirations.

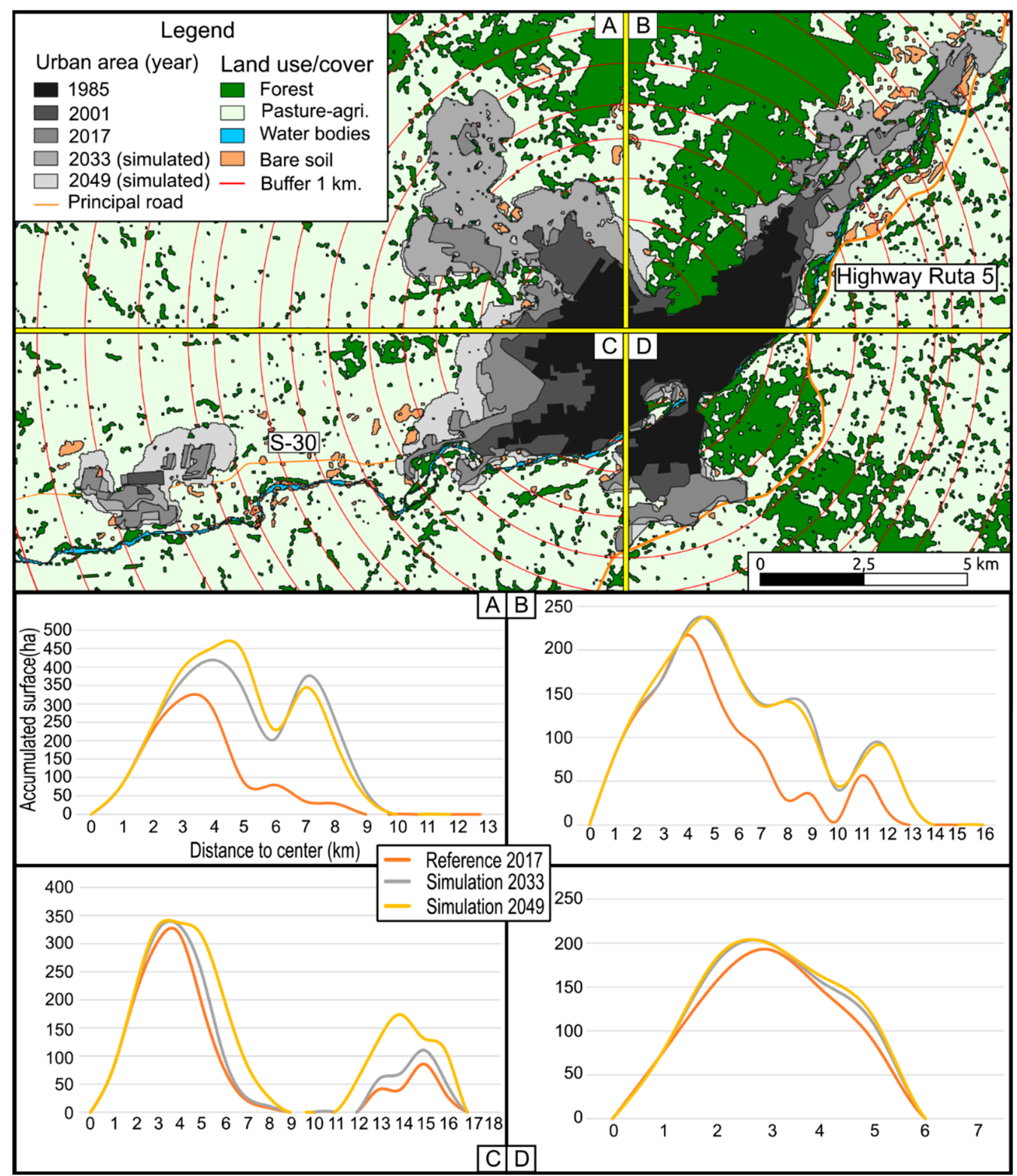

Figure 6. Simulation of urban growth of the city of Temuco as a function of distance. Source: Authors' compilation.

The above analysis could be further based on the distances and the growth that will be experienced, which can be seen in Figure 6. It clearly shows where Labranza and Temuco would have a presence on the surface. Regarding the former, we would see it consume land up to $3 \mathrm{~km}$ from its center with a clear presence up to the first $2 \mathrm{~km}$, and a slight increase in the third and last kilometer.

For its part, Temuco's presence, which could reach up to about $14 \mathrm{~km}$ from the center, is characterized both by its expansion toward the north side in the direction of the Cajon and Vilcún areas, in addition to its conurbation with Padre Las Casas and the modeled urbanization toward the north of the city parallel to Cerro Nielol and the forested areas 
nearby, although due to its current configuration, the greatest presence will be in the first $7 \mathrm{~km}$, as growth will cease to be clearly upward (see Figure 6).

When this dynamic is analyzed in the context of the status of territorial planning instruments, one can see that the Temuco Zoning Plan has been in force since 2010, with an amendment in 2011 and modifications by means of a sectional plan for the Las Encinas sector in 2012. However, the territory in question does not have a plan in force at the intermunicipal level, a situation that is repeated with Padre Las Casas. In this sense, it is important to observe that limiting factors such as the presence of 'Mercedes de Tierra' (indigenous property grants) have not been an obstacle to the expansion and projection simulated. On the contrary, one can see that the communities have remained in the midst of urban expansion [39], and this is therefore reflected in the inorganic growth of the city.

Notwithstanding the results obtained, the method has certain weaknesses that must be considered, such as the "speckle" or "salt-and-pepper" effect of the modeling. This is characterized by generating a series of patches that appear as part of the simulations distributed in a random and disorganized way, when in practice they should be agglomerated.

Despite this, it mostly presented itself in the projection of the base year (2017) and less so in the others. For this situation, the important thing is not to consider them as was done within the analysis carried out, as they are precisely differentiated from the clusters that the model does manage to determine which are the ones that indicate spatial trends and relations.

In addition to this-as has already been outlined in previous paragraphs-the diffuse planes of the growth hubs are linked to Mapuche enclaves, which are indicated as a constraint in Table 1 as they cannot be annexed for urban use. In this sense, diffuse and at times discontinuous growth may be a trend in the morphology that the city is taking on.

One of the last aspects to be highlighted is the lack of refinement or reliability of the location vector layers of Mapuche communities or their property. Without doubt there is a need to achieve greater transparency and make more information available to allow more robust results and analyses to be generated. While the country has made progress, it is a far cry from countries with robust, referenced, and reliable information.

Lastly, it should be noted that in Temuco's case, generating binding urban planning instruments is a priority, as problems have already emerged in terms of diffuse land expansion, and it is projected that growth will not be very harmonious in the next 30 years, together with the presence of indigenous territories whose legal status protects them from intervention, posing a challenge in the matter and raising the need to reduce future conflicts. In this sense, the implementation of Regional Territorial Organization Plans that will regulate rural space through Law 21,070 of 2018 should incorporate this issue as a priority element in their elaboration. Along the same line, strengthening the authority of regional governments in territorial planning is another variable that will allow the complexity of this task to be addressed.

Author Contributions: Conceptualization, Francisco Maturana; methodology, Francisco Maturana and Mauricio Morales; software, Carlos Vielma, Mauricio Morales and Marco A. Peña; validation, Fernando Peña-Cortés, Mauricio Morales and Marco A. Peña; formal analysis, Francisco Maturana and Fernando Peña-Cortés; writing - original draft preparation, Francisco Maturana and Mauricio Morales; writing-review and editing, Francisco Maturana and Fernando Peña-Cortés; visualization, Francisco Maturana and Fernando Peña-Cortés All authors have read and agreed to the published version of the manuscript.

Funding: This research was funded by FONDECYT of Agencia Nacional de Investigación (ANID), Chile, grant number 11150087 and 1181954.

Acknowledgments: The authors would like to thank the anonymous reviewers for their helpful and valuable comments and suggestions.

Conflicts of Interest: The authors declare no conflict of interest. 


\section{References}

1. United Nations World Urbanization Prospects. The 2018 Revision; UNWUP: New York, NY, USA, 2019.

2. Batty, M. The New Science of Cities; The MIT Press: Cambridge, MA, USA, 2013; ISBN 9780262318235.

3. Barthelemy, M. The Structure and Dynamics of Cities; Cambridge University Press: Cambridge, UK, 2016 ; ISBN 9781316271377.

4. Benenson, I.; Torrens, P.M. Geosimulation; Wiley: Hoboken, NJ, USA, 2004; ISBN 9780470843499.

5. Rana, S.; Sharma, J. Frontiers of Geographic Information Technology; Springer: Berlin/Heidelberg, Germany, 2006; ISBN 3-540-25685-7.

6. Pontius, R.G.; Chen, H. Land Change Modeling with GEOMOD. In IDRISI Andes Help Contents; Clark University: Worcester, MA, USA, 2006.

7. Arsanjani, J.J. Dynamic Land Use/Cover Change Modelling; Springer: Berlin/Heidelberg, Germany, 2012; ISBN 978-3-642-23704-1.

8. Kumar, R.; Nandy, S.; Agarwal, R.; Kushwaha, S.P.S. Forest cover dynamics analysis and prediction modeling using logistic regression model. Ecol. Indic. 2014, 45, 444-455. [CrossRef]

9. Nath, B.; Wang, Z.; Ge, Y.; Islam, K.P.; Singh, R.; Niu, Z. Land Use and Land Cover Change Modeling and Future Potential Landscape Risk Assessment Using Markov-CA Model and Analytical Hierarchy Process. ISPRS Int. J. Geo-Inf. 2020, 9, 134. [CrossRef]

10. Hamad, R.; Balzter, H.; Kolo, K. Predicting Land Use/Land Cover Changes Using a CA-Markov Model under Two Different Scenarios. Sustainability 2018, 10, 3421. [CrossRef]

11. Zhou, L.; Dang, X.; Sun, Q.; Wang, S. Multi-scenario simulation of urban land change in Shanghai by random forest and CA-Markov model. Sustain. Cities Soc. 2020, 55, 2045. [CrossRef]

12. Ravetz, J.; Fertner, C.; Nielsen, T.S. The Dynamics of Peri-Urbanization. In Peri-Urban Futures: Scenarios and Models for Land Use Change in Europe; Nilsson, K., Pauleit, S., Bell, S., Aalbers, C., Sick Nielsen, T., Eds.; Springer: Berlin/Heidelberg, Germany, 2013; pp. 13-44.

13. Lima, M.L.; Zelaya, K.; Massone, H. Groundwater Vulnerability Assessment Combining the Drastic and Dyna-Clue Model in the Argentine Pampas. Environ. Manag. 2011, 47, 828-839. [CrossRef] [PubMed]

14. Batty, M. A strategy for generating and testing models of migration and urban growth. Reg. Stud. 1983, 17, 223-236. [CrossRef]

15. Fahmi, F.Z.; Hudalah, D.; Rahayu, P.; Woltjer, J. Extended urbanization in small and medium-sized cities: The case of Cirebon, Indonesia. Habitat Int. 2014, 42, 1-10. [CrossRef]

16. Maturana, F.; Sposito, B.M.; Bellet, C.; Arenas, F.; Henríquez, C. Sistemas Urbanos y Ciudades Medias en Iberoamérica; Serie GeoLibros: Santiago, Chile, 2017.

17. Maturana, F.; Rojas, A. Ciudades Intermedias en Chile: Territorios Olvidados; RIL Editor: Santiago, Chile, 2015.

18. Henderson, V. Medium size cities. Reg. Sci. Urban Econ. 1997, 27, 583-612. [CrossRef]

19. Instituto Nacional de Estadísticas. Censo Nacional de Población 2017; Base Redatam: Santiago, Chile, 2017.

20. Maturana, F.; Rojas, A.; Salas, R. Dinámicas espaciales y transición hacia la articulación de espacios metropolitanos. El caso de Temuco y su hinterland, Chile. Cuad. Geográficos 2018, 57. [CrossRef]

21. Mendoza, R.F.; Peterson, A.V.; Peñaloza, O.J.; Burrows, S.A. Definiendo el Temuco metropolitano: Consideraciones para un nuevo modelo de urbanización extendida en la Araucanía. Arquit. Urban Sustentabilidad 2020. [CrossRef]

22. Salazar, G.; Irarrázaval, F.; Fonck, M.; Salazar, G.; Irarrázaval, F.; Fonck, M. Ciudades intermedias y gobiernos locales: Desfases escalares en la Región de La Araucanía, Chile. EURE 2017, 43, 161-184. [CrossRef]

23. Garín, A.; Salvo, S.; Bravo, G. Segregación residencial y políticas de vivienda en Temuco: 1992-2002. Rev. Geogr. Norte Gd. 2009, 113-128. [CrossRef]

24. Gallo, B.C. El conflicto mapuche como lucha por el reconocimiento: La necesidad de una nueva clave de lectura. Izquierdas 2020, 49. [CrossRef]

25. Kokaly, R.F. Investigating a physical basis for spectroscopic estimates of leaf nitrogen concentration. Remote Sens. Environ. 2001, 75, 153-161. [CrossRef]

26. Peña, M.A.; Brenning, A.; Sagredo, A. Constructing satellite-derived hyperspectral indices sensitive to canopy structure variables of a Cordilleran Cypress (Austrocedrus chilensis) forest. ISPRS J. Photogramm. Rem. Sens. 2012, 74, 1-10. [CrossRef]

27. Morales, M.; Maturana, F. Análisis de patrones espaciales en la expansión urbana de ciudades intermedias. El caso de San Fernando, Chile. Cuad. Vivienda Urban. 2019, 12, cvu12-cvu24. [CrossRef]

28. Beinat, E.; Nijkamp, P. Multicriteria Analysis for Land-Use Management; Springer Netherlands Environment \& Management: Dordrecht, The Netherlands, 1998; Volume 9, ISBN 978-90-481-5077-9.

29. Conadi, Sistema Integrado de Información CONADI SIIC. Available online: http:/ / siic.conadi.cl (accessed on 19 January 2021).

30. Manuschevich, D.; Beier, C.M. Simulating land use changes under alternative policy scenarios for conservation of native forests in south-central Chile. Land Use Policy 2016, 51, 350-362. [CrossRef]

31. Borsdorf, A. Cómo modelar el desarrollo y la dinámica de la ciudad latinoamericana. EURE 2003, 29, 37-49. [CrossRef]

32. Kharat, G.; Raut, R.; Kamble, S.S.; Kamble, S.J. The application of Delphi and AHP method in environmentally conscious solid waste treatment and disposal technology selection. Manag. Environ. Qual. Int. J. 2016, 27, 427-440. [CrossRef]

33. Batty, M. Cities and Complexity: Understanding Cities with Cellular Automata, Agent-Based Models, and Fractals; The MIT Press: Cambridge, MA, USA, 2007; ISBN 0262524791.

34. Pontius, R. Quantification error versus location error in comparison of categorical maps. Photogramm. Eng. Remote Sens. 2000, 66, 1011-1016. 
35. Fan, Y.; Zhu, X.; He, Z.; Zhang, S.; Gao, J.; Chen, F.; Peng, X.; Li, J. Urban Expansion Assessment in Huaihe River Basin, China, from 1998 to 2013 Using Remote Sensing Data. J. Sens. 2017, 2017, 1201. [CrossRef]

36. Zhang, X.; Bai, Z.; Fan, X.; Lu, Y.; Cao, Y.; Zhao, Z.; Sun, Q.; Pan, J. Urban Expansion Process, Pattern, and Land Use Response in an Urban Mining Composited Zone from 1986 to 2013. J. Urban Plan. Dev. 2016, 142, 6014. [CrossRef]

37. Vergara, L. Medianización social y transformaciones residenciales recientes en ciudades de La Araucanía. Cult. Hombre Soc. 2019, 29, 36-60. [CrossRef]

38. Paulsen, A.; Rodríguez, L.; Hidalgo, R. Los espacios de furia. Política y ciudad a través de las luchas urbanas por la vivienda en Santiago de Chile (1990-2016). Cad. Metrópole 2019, 21, 763-782. [CrossRef]

39. Peña, F.; Escalona, M. Expansión urbana en la intercomuna Araucanía Centro. Alteraciones sobre las áreas rurales. In Chile: Del País Urbano al País Metropolitano del País Urbano al País Metropolitano; Hidalgo, R., De Mattos, C., Arenas, F., Eds.; Pontificia Universidad Católica de Chile: Santiago, Chile, 2009; pp. 389-398. 